\title{
Complex oxides of copper and manganese as the base material for catalytic suppression of waste gases
}

\author{
L. A. Pimneva, and A. A. Zagorskaya* \\ Industrial University of Tyumen, 625001, Russia
}

\begin{abstract}
The composite material "ionite-sorbed ions"was obtained by ion exchange technology. The conditions for obtaining the composite material "ionite-sorbed ions"are studied. In the thermolysis of cationite with sorbed ions, the synthesis of complex oxide is carried out between ions located at atomic distances from each other. This facilitates and accelerates the formation of complex oxide. Thermolysis of carboxyl cationite KB-4P-2 with sorbed copper and manganese ions was performed at temperatures from $250-950^{\circ} \mathrm{C}$. Control of the thermolysis mechanism of the composite material "ionite-sorbed ions" was carried out using thermograms. According to the scanning electron microscopy data, the obtained powder of complex copper and manganese oxide has a good crystallite structure. Data x-ray diffraction analysis confirmed the crystallization of a complex oxide of copper and manganese in orthorhombic crystal structure. A method for the synthesis of complex copper and manganese oxide powder based on the thermolysis process of the composite material "ionite-sorbed ions", which has catalytic properties, has been developed.
\end{abstract}

\section{Introduction}

One of the consequences of man-made impact on the environment is the intake of harmful substances, which worsens the state of atmospheric air. Energy is the largest source of emissions into the atmosphere of solid particles (soot, dust, ash), sulfur oxides, nitrogen, as well as in smaller amounts of carbon oxides. Industrial enterprises and urban transport lead to an increase in the volume of harmful substances entering the atmosphere $[1,2]$. The process of cleaning gas emissions can be based on catalytic methods. Recently, much attention has been paid to the development of new catalytic systems for the removal of harmful exhaust gases from industrial plants and internal combustion engines of cars $[3,4]$. Numerous studies are being conducted to obtain catalysts that can purify gases from harmful compounds [5-7]. The ability of the catalyst to interact with various gaseous chemical compounds depends on the method of preparation of the catalyst. Only the combination of several metal oxides makes it possible to convert harmful polluting oxides into harmless ones in the exhaust gases.

The aim of the study is to develop methods for obtaining complex copper and manganese oxide with catalytic properties, to study the thermolysis of cationite with sorbed copper and manganese ions, and to study the crystal structure of the complex oxide.

\section{Materials and methods}

A complex oxide of copper and manganese were obtained using ion-exchange technology with the use of carboxylic cation exchanger KB-4p-2.

Scanning electron microscopy was performed on a JEOL JSM 6510 LV electron microscope.

$\mathrm{X}$-ray diffraction analysis (XRD) was performed on a BRUKER D2 PHASER diffractometer with a lynxeye linear detector (Cuka radiation, Ni filter). The structure was refined by the Rietveld method in the DIFFRAC. TOPAS program.

Infrared spectroscopy was performed on an IR Fourier spectrometer FSM 1201. The sample for the study was prepared in the form of a tablet with calcined potassium bromide.

Thermogravimetric analysis of the initial materials and synthesized samples was performed on a $\mathrm{Q}-1500 \mathrm{D}$ derivatograph. The size of the hitch was from 0.4 to 1.5 g. The temperature range of the thermal analysis was $20-$ $100^{\circ} \mathrm{C}$, the heating rate varied from 2,5 to $20^{\circ} \mathrm{C}$ per minute. Temperature measurement accuracy $\pm 10^{\circ} \mathrm{C} /$.

\section{Results}

A method for obtaining fine powders of complex oxides based on Sol-gel technology using thermolysis of ionites with initially sorbed metal ions in a given ratio has been developed. During the joint sorption of copper and manganese ions on the carboxyl cationite KB-4P-2, there

Corresponding author: zagorskajaaa@tyuiu.ru 

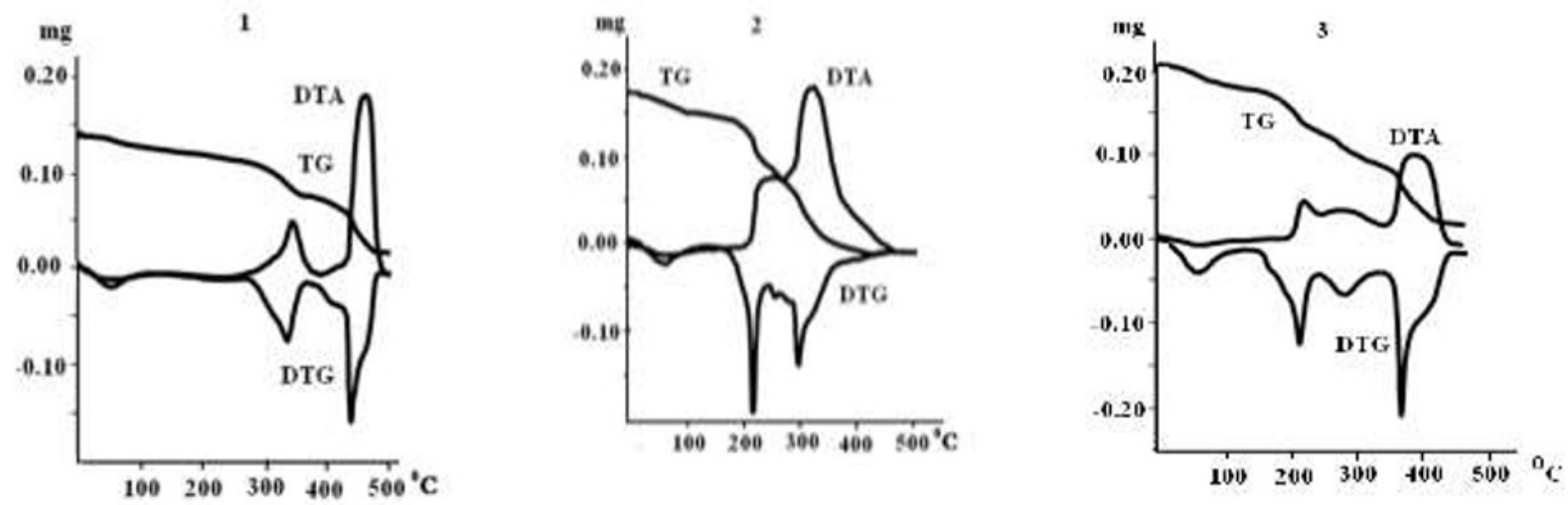

Fig. 1. Thermograms of KB-4P-2 cationite in $\mathrm{Mn}^{2+}(1)$ and $\mathrm{Cu}^{2+}(2)-$ forms in the joint presence (3).

are many interrelated factors: the shape of the ionite, the composition of the eluent, and the temperature. To obtain the complex oxide, carboxyl cationite in ammonium form was taken and copper and manganese ions were sorbed in the ratio of $76 \%$ copper and $24 \%$ manganese.

In the thermolysis of cationite with sorbed ions, the synthesis of complex oxide is carried out between ions located at atomic distances from each other. This facilitates and accelerates the formation of complex oxide. As a result, the product is a granulate that repeats the shape of the ionite grain [8,9]. Thermolysis of carboxyl cationite KB-4P-2 with sorbed copper and manganese ions was performed at temperatures from $250-950{ }^{\circ} \mathrm{C}$. The resulting composite material "ionitesorbed ions" was sequentially heated over time: at a temperature of $110^{\circ} \mathrm{C}$ within 2 hours; at a temperature of $250^{\circ} \mathrm{C}-3$ hours; at a temperature of $410^{\circ} \mathrm{C}-5$ hours; at a temperature of $600^{\circ} \mathrm{C}-3$ hours; at a temperature of $950^{\circ} \mathrm{C}-6$ hours. At the last stage of annealing at a temperature of $950^{\circ} \mathrm{C} 1 \mathrm{~h}$, it was heated in an oxygen atmosphere to improve the properties of the complex oxide.

The study of the thermolysis process of carboxyl cationite KB-4P-2 was controlled using thermograms shown in figure 1.

The results of thermograms show that for the ionite in the manganese form, a clearly defined endoeffect and shoulder are observed at temperatures of $80^{\circ} \mathrm{C}, 340^{\circ} \mathrm{C}$, $420^{\circ} \mathrm{C}$ (shoulder) and $440^{\circ} \mathrm{C}$, and for the copper form, endoeffects are manifested at temperatures of $90^{\circ} \mathrm{C}$, $230^{\circ} \mathrm{C}$, and $300^{\circ} \mathrm{C}$. On the thermogram of the copper shape (DTA and DTG curves), endoeffects are clearly visible at $260^{\circ} \mathrm{C}$ (shoulder on DTG) and $280^{\circ} \mathrm{C}$. At the same time characterized by a sharp decrease in mass at the temperature of the third endoeffect $\left(260^{\circ} \mathrm{C}\right)$. Thus, for the manganese and copper forms on the TG curve, there are four sections of the sample mass loss during heating.

During the degradation of a cation exchanger with jointly sorbed ions of manganese and copper, the same tendency of manifestation of endothermic effects is observed. On all three thermograms, an endothermic effect is observed in the temperature range of $70-100^{\circ}$
$\mathrm{C}$, which corresponds to the release of water. Weight loss of up to $15 \%$ corresponds to the humidity of ionite.

In the temperature range of $350-450^{\circ} \mathrm{C}$, the change in the mass reflected on the TG curve occurs thermal destruction of the polymer matrix of the cationite, which is confirmed by IR spectra (Fig. 2).

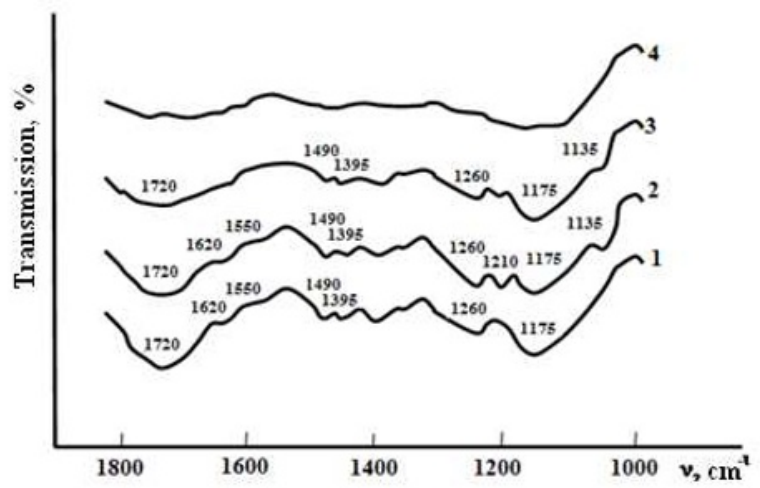

Fig. 2. The IR spectra of the cation $\mathrm{KB}-4 \mathrm{P}-2$ in $\mathrm{NH}_{4}{ }^{+}$- form reinforced ions $\mathrm{Mn}^{2+}, \mathrm{Cu}^{2+}$ at temperatures $25^{\circ} \mathrm{C}(1), 250^{\circ} \mathrm{C}(2)$, $300^{\circ} \mathrm{C}(3), 400^{\circ} \mathrm{C}(4)$.

Changes in the IR spectra occur at $250^{\circ} \mathrm{C}$, which is associated with the destruction of the hydrocarbon framework. In the IR spectra, with an increase in temperature, the band intensity decreases in the region of $1720,1620 \mathrm{~cm}^{-1}$ and in the region of $1490-1395 \mathrm{~cm}^{-1}$. A further increase in temperature leads to a significant change in all physical and chemical parameters. The greatest changes in the cationite occur at $370^{\circ}$, the aliphatic part of the cationite is destroyed and a complete rearrangement of the carboxyl group is observed. Above the temperature of $490^{\circ} \mathrm{C}$, the cationite burns without residue.

According to scanning electron microscopy (Fig. 3), a sample of complex copper and manganese oxide is a microstructure of a dense package of very small crystallites with dimensions of 10-50 microns. A rhombohedral motif can be traced in the structure of the particles.

When forming a bulk product, the granulates retain their primary structure, which ensures high mechanical, 
physico-chemical and technological properties of the finished product.

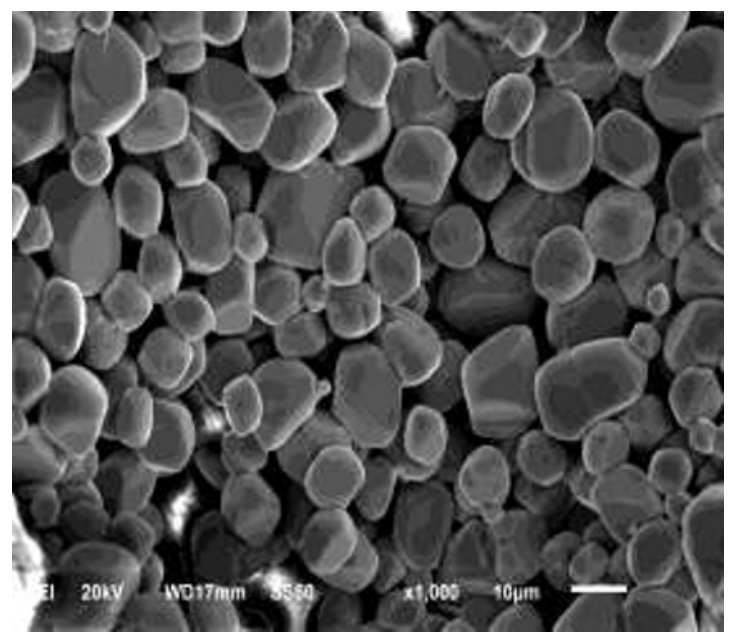

Fig. 3. Electron microscopic image of manganese and copper complex oxide powder.

According to x-ray diffraction analysis (Fig. 4), complex copper and manganese oxide crystallizes in rhombic syngony.

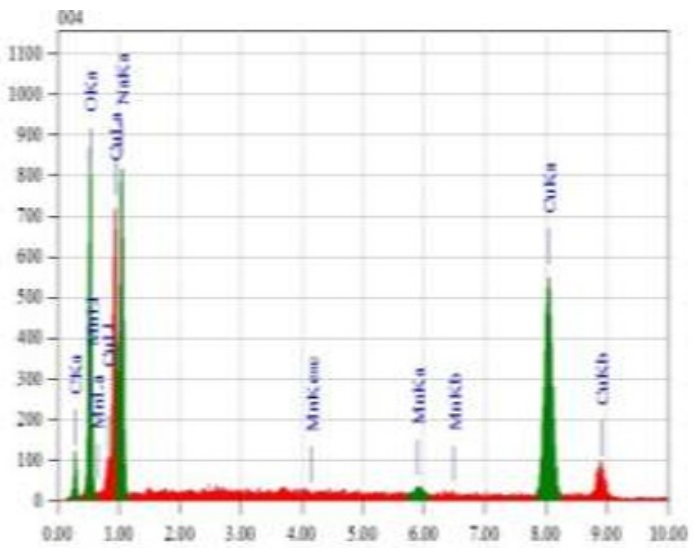

Fig. 4. The diffraction pattern of the complex oxide of manganese media.

According to $\mathrm{x}$-ray phase analysis, the resulting complex oxide is a $\mathrm{CuOMnO}_{2}$ compound. According to electron microscopy data, the powder is formed mainly by spherical particles with a size of 0.5 to 1 microns. The sample also contains smaller particles and their agglomerates (Fig. 5).

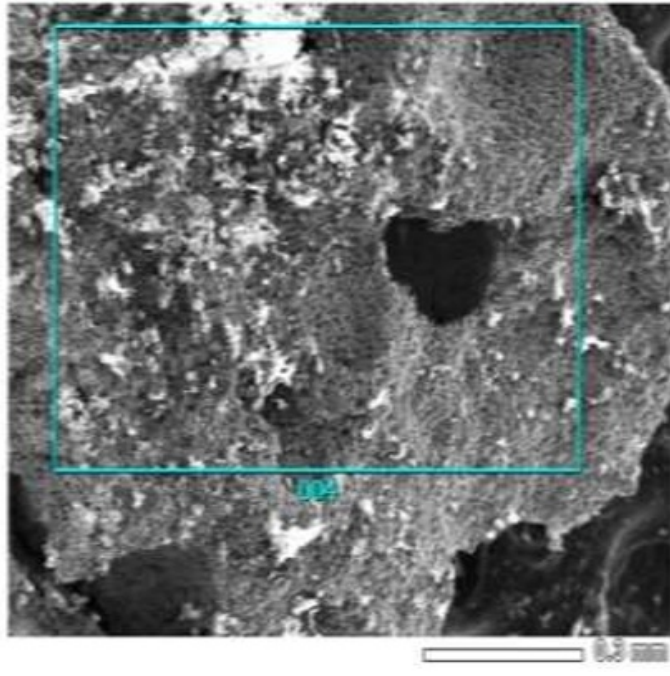

Fig. 5. Electron microscopic image of particles of complex manganese and copper oxide.

\section{Conclusion}

As a result of the study, a method was developed for the synthesis of fine powders of complex oxide Sol-gel technology using pyrolysis of ionites with initially sorbed in a given ratio of cooper and manganese ions. Preliminary tests showed a high activity of the material with respect to carbon and nitrogen compounds. This allows the use of complex metal oxides of copper and manganese for the production of catalytic materials in the practice of suppressing flue gases of heat generating plants. The integration of new generation catalysts into systems for controlling and suppressing gas emissions from stationary sources will reduce the anthropogenic load at the location of air pollution sources, reduce the allocation of territories allocated for sanitary protection zones of heat power facilities, and reduce environmental risks for heat generation systems.

\section{References}

1. Department of Natural Resource Regulation, Forest Relations and Development of the Oil and Gas Complex of the Yamal-Nenets Autonomous District, Report on the «Environmental Situation in the Yamal-Nenets Autonomous District in 2016, Salekhard (2017)

2. Department of subsoil use and ecology of the Tyumen region, Report «On the environmental situation in the Tyumen region in 2016», Tyumen (2017)

3. P.V. Kuvatov, The Use of porous carbon materials as carriers for catalysts, Bashkir chemical journal (2011)

4. O. I. Ahmerov, The Catalysts for purification of gas emissions, Bulletin of Kazan technological University (2014)

5. R.I. Grigorenko, M.G. Davidkhanova, V.N. Grunsky, Investigation of the activity of block cobalt catalysts on the example of carbon 
monoxide oxidation, Advances in chemistry and chemical technology (2017)

6. I.O. Krylov, T.I. Yushina, A.N. Epikhin, K.V. Timashkov, A.A. Strokov, Investigation of the process of catalytic decomposition of methane and carbon monoxide on a natural manganese (ferromanganese) catalyst to produce a nanocarbon material (2014)

7. O.A. Fedyaeva, V.O. Onuchina, Catalytic Oxidation of Carbon Monoxide (Nauka, 2017)

8. L.A. Pimneva, Peculiarities of joint sorption of yetria iont, barium and copper in phase of phosphoro-acid cathionite, Modern problems of science and education 2 (2015)

9. L.A. Pimneva, Thermolysis of phosphoroacid kationitis with sorbyed iontons of yttrium, barium and copper, Fundamental research 8 (2014) 